\title{
Reevaluating the weekend effect on patients with hydrocephalus undergoing operative shunt intervention
}

\author{
Frank J. Attenello, MD, ${ }^{1,2}$ Eisha Christian, MD, ${ }^{1,2}$ Timothy Wen, MPH, ${ }^{2}$ Steven Cen, $\mathrm{PhD},{ }^{1-4}$ \\ Gabriel Zada, MD, ${ }^{1,2}$ Erin N. Kiehna, MD, ${ }^{1,5}$ Mark D. Krieger, MD, ${ }^{1,5}$ J. Gordon McComb, MD, ${ }^{1,5}$ and \\ William J. Mack, MD ${ }^{1,2}$
}

Departments of ${ }^{1}$ Neurosurgery, ${ }^{3}$ Preventive Medicine, and ${ }^{4}$ Radiology, ${ }^{2}$ Keck School of Medicine of USC, University of Southern California, Los Angeles; and ${ }^{5}$ Division of Neurosurgery, Children's Hospital Los Angeles, California

\begin{abstract}
OBJECTIVE Recently published data have suggested an increase in adverse outcomes in pediatric patients after insertion or revision of a ventricular CSF diversion shunt after a same-day weekend procedure. The authors undertook an evaluation of the impact of weekend admission and time to shunting on surgery-related quality outcomes in pediatric patients who underwent ventricular shunt insertion or revision.
\end{abstract}

METHODS Pediatric patients with hydrocephalus who underwent ventriculoperitoneal, ventriculoatrial, or ventriculopleural shunt placement were selected from the 2000-2010 Nationwide Inpatient Sample and Kids' Inpatient Database. Multivariate regression analyses (adjusted for patient, hospital, case severity, and time to shunting) were used to determine the differences in inpatient mortality and routine discharge rates among patients admitted on a weekday versus those among patients admitted on a weekend.

RESULTS There were 99,472 pediatric patients with shunted hydrocephalus, $16 \%$ of whom were admitted on a weekend. After adjustment for disease severity, time to procedure, and admission acuity, weekend admission was not associated with an increase in the inpatient mortality rate $(p=0.46)$ or a change in the percentage of routine discharges $(p=$ 0.98 ) after ventricular shunt procedures. In addition, associations were unchanged after an evaluation of patients who underwent shunt revision surgery. High-volume centers were incidentally noted in multivariate analysis to have increased rates of routine discharge (OR 1.04 [95\% $\mathrm{Cl} 1.01-1.07] ; p=0.02)$.

CONCLUSIONS Contrary to those of previous studies, the authors' data suggest that weekend admission is not associated with poorer outcomes for ventricular shunt insertion or revision. Increased rates of routine discharge were noted at high-volume centers.

http://thejns.org/doi/abs/10.3171/2015.6.PEDS15109

KEY WORDS cerebrospinal fluid; Nationwide Inpatient Sample; pediatric neurosurgery; ventriculoperitoneal shunt; time to surgery; weekend admission; hydrocephalus

$\mathrm{V}$ ENTRICULAR CSF diversion via shunting remains among the most commonly performed neurosurgical procedures. In 2000, the estimated costs of both adult and pediatric shunting procedures were approximately $\$ 1.1$ billion. ${ }^{21}$ Patients who require these shunting procedures present with various disease acuities during both weekdays and weekends. Although many of these shunts are placed electively, patients often present acutely and require either shunt insertion or revision in an urgent or emergent fashion.

With recent widespread availability of national patient treatment data and outcomes, studies have attempted to identify factors associated with adverse outcomes in this population. However, few studies have specifically evaluated the pediatric population. ${ }^{15,24}$ Using the Nationwide Inpatient Sample (NIS) and the Kids' Inpatient Database (KID), recent studies have examined pediatric patients who were admitted and underwent shunt surgery on a weekend, and the results have suggested poorer outcomes, lending support to the deleterious "weekend effect." ${ }^{15}$ Specifically, the so-called weekend effect refers to an apparent increase in complications noted during weekend admissions as a result of limitations in both resources and staff availability. ${ }^{3,19}$

However, when evaluating morbidity and death from weekend admissions, no studies have also evaluated whether time to treatment (urgent or delayed) influences patient

ABBREVIATIONS CCC = complex chronic condition; HCUP = Healthcare Cost and Utilization Project; KID = Kids' Inpatient Database; NIS = Nationwide Inpatient Sample; $\mathrm{RR}=$ rate ratio.

SUBMITTED March 11, 2015. ACCEPTED June 30, 2015.

INCLUDE WHEN CITING Published online November 6, 2015; DOI: 10.3171/2015.6.PEDS15109. 
outcome. Using the NIS and KID data sets, we set out to evaluate on a national level the effects of both weekend admission and time to shunting on outcomes in pediatric patients who have undergone ventricular shunt placement.

\section{Methods \\ Databases}

The KID and NIS are two of the largest pediatric and general inpatient discharge databases in the United States and contain information on millions of discharges per year. The KID and NIS data sets are collected from more than 2500 hospitals and 1000 hospitals, respectively, and provide national estimates of all US hospital discharges. These databases are provided and managed by the Agency for Healthcare Research and Quality's Healthcare Cost and Utilization Project (HCUP; http://www.ahrq. gov/research/data/hcup/). The KID is compiled once every 3 years, and we therefore supplemented the missing years with NIS data when KID data were not available. Nonoverlapping years of the KID (2000, 2003, 2006, and 2009) and NIS (2001-2002, 2004-2005, 2007-2008, and 2010) were used for this study. Because both databases are compiled though the HCUP, the variables and methodologies of data collection are equivalent, so the databases can be combined in a straightforward fashion. Previous studies have combined these databases in a similar manner, and our methods were adapted from these studies. ${ }^{1,8,15,22}$

\section{Study Cohort}

All patients aged 20 years or younger were selected according to the ICD-9-CM diagnosis codes for hydrocephalus (ICD-9-CM 331.3, 331.4, 741.0, 742.3) and procedure codes for ventriculoatrial shunt (ICD-9-CM 02.32), ventriculopleural shunt (ICD-9-CM 02.33), ventriculoperitoneal shunt (ICD-9-CM 02.34), or replacement of a ventricular shunt (ICD-9-CM 02.42). A separate analysis was performed on a cohort of patients who underwent surgery only for revision or replacement of a ventricular shunt (ICD-9-CM 02.42). Procedure and diagnosis codes were validated and successfully used in previous studies that evaluated NIS-documented patients with hydrocephalus. ${ }^{24}$

Patient factors considered in our demographic and multivariate analyses included race (white, black, Hispanic, Asian/Pacific Islander, Native American, or other), payer status (Medicare, Medicaid, private insurance, self-pay, no charge, or other), sex (male or female), and age $(<1,1-4$, $5-9,10-17$, or $>18$ years old). Age was categorized in a manner similar to that of previous studies, with the 18to 20 -year-old category including patients not universally included among pediatric cohorts but included in the KID cohort. ${ }^{24}$ Hospital factors included hospital type (general hospital, children's unit in general hospital, or children's hospital), bed size (small [ $<200$ beds], medium [200-400 beds], or large [ $>400$ beds]), region (Northeast, Midwest, South, or West), teaching status (nonteaching or teaching), location (rural or urban), and annual procedure volume. Institutional shunt procedure volume was categorized as high (> 32 procedures/year, corresponding to $>90$ th percentile) or low ( $<32$ procedures/year). Note that a separate analysis was performed with treatment volume as a continuous variable. Hospital type was assigned based on criteria from the National Association of Children's Hospitals and Related Institutions (NACHRI) and categorized as "not children's hospital by NACHRI," "children's unit in general hospital," or "children's general/specialty hospital." Because the NIS does not contain information regarding the children's hospital type in its database, this data point was extrapolated from KID hospitals that appear in the NIS database, and we used the hospital identification numbers found in the KID linked with their children's hospital status.

Admission severity factors were adjusted for by taking into account the patients' admission type, admission source, and presence of a complex chronic condition (CCC). Admission type was categorized as emergency, urgent, elective, newborn, trauma, or other. Admission source was categorized as emergency department, another hospital, other health facility, or routine admission (newborn or elective). Patient comorbidity status was identified by using the CCC indicators described and validated in the pediatric literature in past studies. CCCs have specific ICD-9$\mathrm{CM}$ codes that were validated by Burns et al. ${ }^{6}$ and Simon et al., ${ }^{23}$ and they are grouped into larger overarching categories, such as neuromuscular malformation, cardiovascular malformation, respiratory issues, renal issues, gastrointestinal issues, hematological or immunology issues, metabolic disorders, other congenital or genetic defects, and malignancies. For example, neuromuscular ICD-9-CM codes included 740.0-742.9, 318.0-318.2, 330.0-330.9, $334.0-334.2$, 335.0-335.9, 343.0-343.9, and 359.0-359.9; cardiovascular malformation codes included 745.0-747.4, 425.0-425.5, 429.1, 426.0-427.4, and 427.6-427.9; respiratory codes included 748.0-748.9; renal codes included 753.0-753.9; gastrointestinal codes included 555.0-555.9 and 571.4-571.9; hematological codes included 282.0282.4 and 282.6-282.9; metabolic codes included 270.0272.9; congenital defect codes included 758.0-758.9 and 756.0-756.5; and malignancy codes included 140.0-208.9 and 235.0-239.9. ${ }^{5}$ Full CCC tables with accompanying descriptions have been provided by Burns et al. ${ }^{6}$

Variables of interest included the time from admission to the shunt procedure and hospital admission day (weekend vs weekday). The KID and the NIS encoded the time to procedure as a variable (number of days) that was subsequently recoded as a categorical variable (same day, 1 day to the procedure, 2 or more days to the procedure) for our analysis. Admissions on a Saturday or Sunday were considered weekend admissions, and those on Monday through Friday were considered weekday admissions. It was not possible to distinguish weekday from weeknight admissions.

Outcomes of interest were inpatient death and routine discharge. Within the KID and the NIS, inpatient death and routine discharge are encoded as patient disposition and are subsequently recoded as dichotomous variables. Routine discharge is defined by the HCUP as standard discharge to home or self-care. ${ }^{7,24}$ In the pediatric population, routine discharge refers primarily to discharge to home with family capable of providing for the child's specific needs.

\section{Statistical Analysis}

Univariate demographic analysis was conducted by us- 
ing survey-adjusted methods for all patient (race, payer status, sex, age), hospital (type, bed size, region, teaching status, location, annual procedure volume), and admission severity (CCC, admission source, admission type) factors. Survey-adjusted methods refer to biostatistical adjustments for determining national estimates using variance estimation methods designed for survey data. The main predictors of interest in our analyses were day of admission (weekend or weekday) and time to procedure after admission (same day, 1 calendar day after admission, or 2 or more calendar days after admission).

Primary analyses included two multivariate Poisson regression models fitted to examine the association (rate ratio [RR]) between weekend admission and time to procedure after admission, with adjustment for patient/hospital/ admission factors and the two outcomes of interest after adjusting for patient (race, payer status, sex, age), hospital (type, bed size, region, teaching status, location, annual procedure volume), and admission severity (CCC, source, type) factors. Secondary analyses were performed with the same outcomes. In one set of secondary analyses, we adjusted for ventriculostomy placement during the inpatient stay, tumor location and pathology, intraventricular hemorrhage, and prematurity, in addition to the patient, hospital, and severity factors noted in the primary analyses. In additional secondary analyses, we restricted the population to only patients with a noncomplex condition, and another set of secondary analyses were restricted to only the population of those who underwent shunt revision (defined by the ICD-9-CM code).

All statistical analyses were performed using SAS 9.4, and a $p$ value of $<0.05$ was predetermined to be statistically significant.

\section{Results \\ Demographics}

From 2000 to 2010 , there were a total of 99,472 pediatric shunt procedures performed, for which time-to-procedure data were available for 80,572 patients. Of these procedures, $1041(1 \%)$ resulted in inpatient death, and 85,915 $(86 \%)$ resulted in a routine discharge. Regarding the time to procedure, $36,172(36 \%)$ were performed on the same day, 15,328 (15\%) were done within 1 day of admission, and $29,073(29 \%)$ were performed within 2 or more days after admission. Of the 99,472 in the sample, 18,899 (19\%) were missing a time-to-procedure value. Of the same-day procedures, a majority $(34,110$ [94\%]) resulted in routine discharge (Table 1). Furthermore, the median time to procedure in our data set was 1 day after admission (IQR $0-4$ days). The majority of patients (84\%) were admitted on a weekday, were white (43\%), had private insurance $(47 \%)$, and were male $(56 \%)$. The majority of procedures were performed in hospitals that had designated teaching status (91\%), whereas they were performed in a children's hospital in $15 \%$ of the admissions. Thirty-nine percent of the admissions were from a routine source, and 38\% of the admissions were emergent (Table 2). Among the institutional subset for which children's hospital status was available, $58 \%$ of high-volume institutions ( $>$ 90th percentile) were children's hospitals, whereas $40 \%$ were children's units of general hospitals.
TABLE 1. Frequency of outcomes stratified by time to procedure

\begin{tabular}{lccc}
\hline & \multicolumn{3}{c}{ No. of Patients $(\%)$} \\
\cline { 2 - 4 } Outcome & $\begin{array}{c}\text { Same Day } \\
(\mathrm{n}=36,172)\end{array}$ & $\begin{array}{c}1 \text { Day } \\
(\mathrm{n}=15,328)\end{array}$ & $\begin{array}{c}\geq 2 \text { Days } \\
(\mathrm{n}=29,073)\end{array}$ \\
\hline Inpatient death & $166(<<1)$ & $112(<<1)$ & $575(2)$ \\
\hline Routine discharge & $34,110(94)$ & $13,733(90)$ & $21,658(74)$ \\
\hline
\end{tabular}

$\ll=$ much less than $1 \%$.

\section{Inpatient Death}

After adjusting for patient (race, payer status, sex, age), hospital (type, bed size, region, teaching status, location, annual procedure volume), and admission severity (CCC, source, type) factors, we examined the inpatient mortality rates after pediatric shunt procedures using day of admission and time to procedure as the main predictors of interest (Table 3). Weekend admissions (versus weekday admissions) were not statistically significantly associated with inpatient mortality rates $(\mathrm{p}=0.46)$. Procedures within 1 day of admission were not significantly different, either $(\mathrm{p}=0.82)$, but procedures 2 or more days after admission resulted in an inpatient mortality rate (RR 2.17 [95\% CI 1.59-2.97]; $\mathrm{p}<0.01$ ) more than double that of procedures performed on the same day of admission (Table 3). Other factors that also reached significance included patient race, case complexity, and admission type. Black (RR 1.44 [95\% CI 1.05-1.98]; $\mathrm{p}=0.03$ ) and Hispanic (RR 1.61 [95\% CI 1.18-2.20]; $\mathrm{p}<0.01$ ) patients were at a higher risk of inpatient death than white patients. Emergency (RR 2.07 [95\% CI 1.34-3.20]; $\mathrm{p}<0.01$ ) and urgent (RR 2.07 [95\% CI 1.33-3.21]; $\mathrm{p}<0.01$ ) admissions were more likely to result in inpatient death than were elective admissions. Complex (at least 1 CCC) cases (RR 3.16 [95\% CI 2.35-4.24]; $\mathrm{p}<0.01)$ were also more likely to result in inpatient death than noncomplex cases (Table 3 ). A time to shunting of $\geq$ 2 days remained significantly associated with death in the population of those who underwent revision shunt surgery only ( $p<0.01$ ), whereas weekend admission continued to show no significant association with death $(\mathrm{p}>0.05)$, as was also seen in the noncomplex shunt cases.

\section{Routine Discharge}

Finally, we analyzed the rates of routine discharge in this patient population (Table 4). Weekend admissions were not statistically different in predicting the likelihood of routine discharge compared with that of weekday admissions (RR 1.00 [95\% CI 0.97-1.03]; $\mathrm{p}=0.98$ ). However, time to procedure was a significant predictor of the likelihood of having a routine discharge. There was a $15 \%$ decreased rate of routine discharge for procedures performed 2 or more days after admission compared with procedures performed within the same day of admission (RR 0.85 [95\% CI 0.82-0.87]; p < 0.01) (Table 4). Evaluation of the revision-alone cohort revealed no association between weekend admission and routine discharge $(\mathrm{p}=$ 0.47 ), whereas time to shunting of $\geq 2$ days remained significantly associated with a decreased likelihood of routine discharge (RR 0.87 [95\% CI 0.83-0.90]; $\mathrm{p}<0.01$ ).

It should be noted that we also adjusted our models in separate analyses for covariates of ventriculostomy placement, prematurity, tumor pathology, and intraventricular 
TABLE 2. Demographics stratified by time to procedure*

\begin{tabular}{|c|c|c|c|}
\hline \multirow[b]{2}{*}{ Demographic } & \multicolumn{3}{|c|}{ No. of Patients (\%) } \\
\hline & Same Day & 1 Day & $\geq 2$ Days \\
\hline Length of stay (days) & 3 & 5 & 29 \\
\hline \multicolumn{4}{|l|}{ Admission day } \\
\hline Weekday & $32,183(89)$ & $12,998(85)$ & $22,845(79)$ \\
\hline Weekend & $3,989(11)$ & $2,329(15)$ & $6,228(21)$ \\
\hline \multicolumn{4}{|l|}{ Race } \\
\hline White & $18,015(50)$ & $7,402(48)$ & $12,353(42)$ \\
\hline Black & $5,170(14)$ & $2,240(15)$ & $4,861(17)$ \\
\hline Hispanic & $5,135(14)$ & $2,652(17)$ & $5,696(20)$ \\
\hline Asian/Pacific Islander & $630(2)$ & $321(2)$ & $717(2)$ \\
\hline Native American & $138(0.4)$ & DS (0) & $88(0.3)$ \\
\hline Other & $1,473(4)$ & $735(5)$ & $1,538(5)$ \\
\hline \multicolumn{4}{|l|}{ Payer } \\
\hline Medicare & $99(0.3)$ & $39(0.3)$ & $85(0.3)$ \\
\hline Medicaid & $15,184(42)$ & $7,310(48)$ & $14,591(50)$ \\
\hline Private insurance & $18,451(51)$ & $6,958(45)$ & $12,381(43)$ \\
\hline Self-pay & $605(2)$ & $295(2)$ & $537(2)$ \\
\hline No charge & $\mathrm{DS}(0)$ & $\mathrm{DS}(0)$ & $51(0.2)$ \\
\hline Other & $1,749(5)$ & $675(4)$ & $1,334(5)$ \\
\hline \multicolumn{4}{|l|}{ Sex } \\
\hline Male & $20,030(55)$ & $8,435(55)$ & $16,617(57)$ \\
\hline Female & $15,846(44)$ & $6,822(45)$ & $12,408(43)$ \\
\hline \multicolumn{4}{|l|}{ Age } \\
\hline$<1 \mathrm{yr}$ & $10,373(29)$ & $5,312(35)$ & $12,652(44)$ \\
\hline $1-4$ yrs & $8,642(24)$ & $3,214(21)$ & $5,360(18)$ \\
\hline $5-9$ yrs & $6,117(17)$ & $2,490(16)$ & $3,581(12)$ \\
\hline $10-17$ yrs & $8,297(23)$ & $3,267(21)$ & $5,087(18)$ \\
\hline$>18$ yrs & $2,742(8)$ & $1,045(7)$ & $2,393(8)$ \\
\hline \multicolumn{4}{|l|}{ Hospital type } \\
\hline General hospital & $2,589(7)$ & $906(6)$ & $2,504(9)$ \\
\hline $\begin{array}{l}\text { Children's unit in general } \\
\text { hospital }\end{array}$ & $5,031(14)$ & $2,141(14)$ & $3,605(12)$ \\
\hline Children's hospital & $5,727(16)$ & $2,550(17)$ & $4,770(16)$ \\
\hline \multicolumn{4}{|l|}{ Hospital bed size } \\
\hline Small $(<200)$ & 6,746 (19) & $2,430(16)$ & $3,722(13)$ \\
\hline Medium (200-400) & $8,143(23)$ & $3,676(24)$ & $6,845(24)$ \\
\hline Large (>400) & $20,676(57)$ & $8,932(58)$ & $17,930(62)$ \\
\hline \multicolumn{4}{|l|}{ Hospital region } \\
\hline Northeast & $6,729(19)$ & $3,664(24)$ & $6,502(22)$ \\
\hline Midwest & $6,652(18)$ & $2,273(15)$ & $3,861(13)$ \\
\hline South & $14,962(41)$ & $6,101(40)$ & $11,549(40)$ \\
\hline West & $7,830(22)$ & $3,290(21)$ & $7,161(25)$ \\
\hline \multicolumn{4}{|l|}{ Hospital teaching status } \\
\hline Nonteaching & $2,975(8)$ & $894(6)$ & $2,151(7)$ \\
\hline Teaching & $32,590(90)$ & $14,144(92)$ & $26,346(91)$ \\
\hline \multicolumn{4}{|l|}{ Hospital location } \\
\hline Rural & $486(1)$ & $179(1)$ & $364(1)$ \\
\hline Urban & $35,078(97)$ & $14,859(97)$ & $28,133(97)$ \\
\hline
\end{tabular}

(continued)
TABLE 2. Demographics stratified by time to procedure* (continued)

\begin{tabular}{cccc}
\hline & \multicolumn{3}{c}{ No. of Patients (\%) } \\
\cline { 2 - 4 } Demographic & Same Day & 1 Day & $\geq 2$ Days \\
\hline Annual procedure volume & & & \\
\hline Low (<32 cases/yr) & $10,946(30)$ & $4,625(30)$ & $10,983(38)$ \\
\hline High (>32 cases/yr) & $25,226(70)$ & $10,703(70)$ & $18,090(62)$ \\
\hline CCCs & & & \\
\hline$\geq 1$ & $19,354(54)$ & $9,173(60)$ & $19,564(67)$ \\
\hline 0 & $16,819(46)$ & $6,155(40)$ & $9,509(33)$ \\
\hline Admission source & & & \\
\hline Emergency department & $8,492(23)$ & $5,765(38)$ & $8,688(30)$ \\
\hline Another hospital & $999(3)$ & $1,171(8)$ & $4,708(16)$ \\
\hline Other health facility & $395(1)$ & $197(1)$ & $496(2)$ \\
\hline Routine & $18,691(52)$ & $4,808(31)$ & $8,233(28)$ \\
\hline Admission type & \multicolumn{3}{c}{} \\
\hline Emergency & $10,941(30)$ & $7,379(48)$ & $12,482(43)$ \\
\hline Urgent & $5,551(15)$ & $3,266(21)$ & $5,707(20)$ \\
\hline Elective & $14,164(39)$ & $1,801(12)$ & $2,670(9)$ \\
\hline Newborn & $138(0.4)$ & $330(2)$ & $2,599(9)$ \\
\hline Trauma & DS (0) & DS (0) & $136(0.5)$ \\
\hline Missing & $5,337(15)$ & $2,524(16)$ & $5,479(19)$ \\
\hline
\end{tabular}

DS = Data suppressed per the HCUP Data User Agreement.

* Data on individual factors not recorded in the NIS/KID are not included.

hemorrhage or with treatment volume as a continuous variable. After adjustment, a time to shunting of $\geq 2$ days remained significant for increased mortality rates and decreased rates of routine discharge, whereas weekend admission persisted in showing no significant association with these outcomes. In addition, when subsetted for noncomplex cases only, these associations still held true.

\section{Discussion}

Using the 2000-2010 NIS and KID databases, we evaluated the effect of weekend admission on the outcome of 99,472 pediatric patients who needed operative ventricular CSF diversion, $16 \%$ of whom were admitted on a weekend. Common and reliable measures of outcome, previously used in previous studies that evaluated both populations with a shunt and negative effects of weekend admission, are death and routine discharge (as a marker of morbidity) rates (Table 1). Contrary to what has been reported from several studies, we found no adverse effect of weekend admission on mortality or routine discharge rates when we included time to shunting in our multivariate analysis.

These results run counter to those of several previous studies that cited a weekend effect with poorer outcomes in patients admitted on a weekend. . $^{3,4,9,14,19}$ Recent publications included pediatric patients who underwent CSF shunt surgery among those who have experienced the weekend effect, with adverse outcomes seen in same-day weekend shunt revisions. ${ }^{15}$ Authors have noted a risk of death, blood transfusion, and procedural complications for urgent weekend surgical admissions higher than that in patients who had urgent surgery during the week. ${ }^{15}$ However, these 
TABLE 3. Multivariable analysis of inpatient death

\begin{tabular}{|c|c|c|c|}
\hline Factor & RR & $95 \% \mathrm{Cl}$ & p Value* \\
\hline \multicolumn{4}{|l|}{ Admission day } \\
\hline Weekend & 1.10 & $0.85-1.43$ & 0.46 \\
\hline Weekday & Reference & & \\
\hline \multicolumn{4}{|l|}{ Days to procedure } \\
\hline 1 day & 1.05 & $0.69-1.59$ & 0.82 \\
\hline$\geq 2$ days & 2.17 & $1.59-2.97$ & $<0.01$ \\
\hline Same day & Reference & & \\
\hline \multicolumn{4}{|l|}{ Hospital type } \\
\hline Not a children's hospital & 1.21 & $0.76-1.92$ & 0.42 \\
\hline Children's unit & 1.22 & $0.81-1.83$ & 0.35 \\
\hline Children's hospital & Reference & & \\
\hline \multicolumn{4}{|l|}{ Hospital bed size } \\
\hline Medium (200-400) & 1.07 & $0.72-1.59$ & 0.74 \\
\hline Large (>400) & 1.13 & $0.76-1.70$ & 0.54 \\
\hline Small $(<200)$ & Reference & & \\
\hline \multicolumn{4}{|l|}{ Hospital region } \\
\hline Midwest & 0.89 & $0.60-1.34$ & 0.58 \\
\hline South & 0.96 & $0.71-1.32$ & 0.81 \\
\hline West & 0.68 & $0.42-1.09$ & 0.11 \\
\hline Northeast & Reference & & \\
\hline \multicolumn{4}{|l|}{ Hospital teaching status } \\
\hline Teaching & 1.24 & $0.77-2.01$ & 0.37 \\
\hline Nonteaching & Reference & & \\
\hline \multicolumn{4}{|l|}{ Hospital location } \\
\hline Urban & 3.64 & $0.50-26.21$ & 0.20 \\
\hline Rural & Reference & & \\
\hline \multicolumn{4}{|l|}{ Annual procedure volume } \\
\hline High & 0.86 & $0.67-1.12$ & 0.27 \\
\hline Low & Reference & & \\
\hline \multicolumn{4}{|l|}{ CCCs } \\
\hline$\geq 1$ & 3.16 & $2.35-4.24$ & $<0.01$ \\
\hline 0 & Reference & & \\
\hline \multicolumn{4}{|l|}{ Admission source } \\
\hline Emergency department & 0.95 & $0.68-1.32$ & 0.75 \\
\hline Another hospital & 2.06 & $1.48-2.88$ & $<0.01$ \\
\hline Other health facility & 2.04 & $1.02-4.06$ & 0.04 \\
\hline Routine & Reference & & \\
\hline \multicolumn{4}{|l|}{ Admission type } \\
\hline Emergency & 2.07 & $1.34-3.20$ & $<0.01$ \\
\hline Urgent & 2.07 & $1.33-3.21$ & $<0.01$ \\
\hline Newborn & 4.81 & $2.92-7.94$ & $<0.01$ \\
\hline Trauma & 1.84 & $0.25-13.70$ & 0.55 \\
\hline Elective & Reference & & \\
\hline
\end{tabular}

* Values in boldface indicate a significant result.

previous studies did not consistently incorporate multivariate analysis to specifically include time to procedure to account for outcomes observed after weekend admission.

Studies that evaluated the weekend effect often focused on the question of increased disease severity and case complexity among weekend admissions. Bell and Redelmeier ${ }^{3}$
TABLE 4. Multivariable analysis of routine discharge

\begin{tabular}{|c|c|c|c|}
\hline Factor & $\mathrm{RR}$ & $95 \% \mathrm{Cl}$ & p Value* \\
\hline \multicolumn{4}{|l|}{ Admission day } \\
\hline Weekend & 1.00 & $0.97-1.03$ & 0.98 \\
\hline Weekday & Reference & & \\
\hline \multicolumn{4}{|l|}{ Days to procedure } \\
\hline 1 day & 0.98 & $0.95-1.01$ & 0.23 \\
\hline$\geq 2$ days & 0.85 & $0.82-0.87$ & $<0.01$ \\
\hline Same day & Reference & & \\
\hline \multicolumn{4}{|l|}{ Hospital type } \\
\hline Not a children's hospital & 0.96 & $0.91-1.01$ & 0.13 \\
\hline Children's unit & 0.96 & $0.92-1.01$ & 0.09 \\
\hline Children's hospital & Reference & & \\
\hline \multicolumn{4}{|l|}{ Hospital bed size } \\
\hline Medium (200-400) & 1.01 & $0.97-1.06$ & 0.51 \\
\hline Large $(>400)$ & 0.99 & $0.94-1.03$ & 0.48 \\
\hline Small $(<200)$ & Reference & & \\
\hline \multicolumn{4}{|l|}{ Hospital region } \\
\hline Midwest & 1.08 & $1.03-1.12$ & $<0.01$ \\
\hline South & 1.10 & $1.06-1.14$ & $<0.01$ \\
\hline West & 1.09 & $1.04-1.15$ & $<0.01$ \\
\hline Northeast & Reference & & \\
\hline \multicolumn{4}{|l|}{ Hospital teaching status } \\
\hline Teaching & 1.01 & $0.96-1.06$ & 0.74 \\
\hline Nonteaching & Reference & & \\
\hline \multicolumn{4}{|l|}{ Hospital location } \\
\hline Urban & 0.94 & $0.84-1.06$ & 0.32 \\
\hline Rural & Reference & & \\
\hline \multicolumn{4}{|l|}{ Annual procedure volume } \\
\hline High & 1.04 & $1.01-1.07$ & 0.02 \\
\hline Low & Reference & & \\
\hline \multicolumn{4}{|l|}{ cCCs } \\
\hline$\geq 1$ & 0.98 & $0.96-1.00$ & 0.08 \\
\hline 0 & Reference & & \\
\hline \multicolumn{4}{|l|}{ Admission source } \\
\hline Emergency department & 0.98 & $0.95-1.02$ & 0.41 \\
\hline Another hospital & 0.96 & $0.93-1.00$ & 0.05 \\
\hline Other health facility & 2.04 & $1.02-4.06$ & 0.04 \\
\hline Routine & Reference & & \\
\hline \multicolumn{4}{|l|}{ Admission type } \\
\hline Emergency & 1.00 & $0.97-1.03$ & 0.99 \\
\hline Urgent & 0.78 & $0.74-0.82$ & $<0.01$ \\
\hline Newborn & 0.75 & $0.66-0.84$ & $<0.01$ \\
\hline Trauma & 0.69 & $0.54-0.84$ & $<0.01$ \\
\hline Elective & Reference & & \\
\hline
\end{tabular}

* Values in boldface indicate a significant result.

noted that their results could not account for the admission of sicker patients over the weekend, which could explain an increase in adverse events. Another group demonstrated that sicker patients come in over the weekend, thereby explaining increased mortality rates and adverse events. ${ }^{19}$ We attempted to adjust for disease severity by incorpo- 
rating variables of case complexity, admission source, and urgency of admission within our multivariate analysis. It was not surprising that complex cases, emergency department admissions, and emergent/urgent acuity admissions were each significantly associated with death in multivariate analysis. Similarly, Hixson et al., ${ }^{18}$ despite noting an increased mortality rate in their pediatric intensive care population over the weekends, noted that this phenomenon resolved in multivariate analysis that accounted for the differences in types and severity of weekend admissions.

In multivariate analysis, after adjustment for admission source, urgency, and severity, time to shunting remained significantly associated with increases in mortality and nonroutine discharge rates in both the overall cohort and the revision-shunt cohort. The concept that adverse outcomes follow delays in treatment is not entirely novel. Results of a Danish study on death after hip fracture suggested that in-hospital death was associated with surgical delay rather than weekend or holiday admission. ${ }^{10}$ Increases in length of intensive care unit stays have been noted to correlate with a higher incidence of infection. ${ }^{27}$ In the neurosurgical literature, traumatic neurosurgical injuries of the spine have been associated with improved outcomes after early decompression. ${ }^{12}$ The goals of urgent neurological surgery have historically revolved around the prevention of secondary injury caused by delayed ischemia and direct compression of the brain and spinal cord. When evaluating extended timelines of surgical intervention, the authors of studies on long-term hydrocephalus suggested that earlier intervention in cases of congenital hydrocephalus result in greater postoperative increases in cortical mantle thickness and improved neuropsychological development on testing. ${ }^{26}$

However, no definitive conclusions can be made about time to shunting. Patients with an extended waiting time before surgery often have complex comorbidities and underlying pathologies that necessitate long-term stabilization and workup. Given the significant time to shunting noted in the long cohort ( $>2$ days to shunting), it is likely that these patients with a more complex condition have significant medical/surgical issues that have greater effects than those encoded by our CCC adjustment in multivariate analysis. These issues may include being transferred from another hospital, being newborns, or being classified as having an emergent/urgent condition that needs to be attended to before operative intervention for shunt insertion/revision, which results in a significant increase in the time to surgery. The CCC variable was particularly appropriate for adjusting for these comorbidities, and using it helped to identify a population of children comprising $10 \%$ of admissions but accounting for $23 \%-26 \%$ of inpatient hospital days and $42 \%-43 \%$ of the deaths. ${ }^{6,23}$ It is this high-complexity group with CCCs (with a time to surgery of $\geq 2$ days) that had a $2 \%$ mortality rate, whereas those who were of low complexity and underwent surgery on the same or the first day had a mortality rate well below $1 \%$. The $\geq 2$-day group also had a significantly decreased percentage of routine discharges and an average length of stay of 29 days, whereas the same and 1-day groups had average lengths of stay of 3 and 5 days, respectively.

Another finding was that institutions with a high shunting volume were associated with a significant increase in routine discharge $(\mathrm{p}=0.01)$. This association between increased volume and improved outcome has been demonstrated in other fields. ${ }^{11,17}$ A study completed in 2002 systematically reviewed 20 years of research on the relationship between volume and outcome based on 135 population-based studies; $71 \%$ of all the studies of hospital volume reported a statistically significant association between higher volume and improved health outcomes.

Finally, the African American and Hispanic races were noted to be associated with a significantly increased risk of inpatient death after shunt placement. These results are similar to those noted in a previous study of pediatric patients with a shunt. ${ }^{2}$ Although the previous analysis made use of only the KID cohorts in 2000, 2003, 2006, and 2009 and did not adjust for the multiple factors we used in our analysis (presence of a CCC), the effect was noted again. Similar disparities have been noted after pediatric surgeries. ${ }^{20,25}$ Although the causes of these disparities are not clear, authors have postulated that outcomes may vary as a result of racial disparities in referral patterns and regional differences in access to health care. ${ }^{13}$

Multiple limitations were present in this study, primarily from the use of large population-based administrative databases. NIS data are limited to events that occur during a single inpatient stay; therefore, data on shunt infections and malfunctions after discharge cannot be captured. ${ }^{7}$ Although these outcomes are more commonly pursued in shunting studies, our focus on death and discharge disposition mirrored that of previous weekend-effect studies, which allowed comparison. Another limitation was that the data are input through ICD-9-CM codes by hospital staff members with a wide variation in level of both training and oversight. Potential for recording bias results in estimates of coding accuracy of approximately $80 \%$.5,16 This bias may affect the coding of not only diagnoses but also of covariates and noted complications. Other variables of interest were unavailable for our analysis. For example, although the number of previous revisions has been suggested as a strong predictor of outcome, this variable was not available for analysis. The information provided in the databases about time to procedure was not a continuum; thus, surgery on a patient within 24 hours of being admitted just after midnight would count as same-day surgery, whereas surgery on the same patient 25 or $\geq 48$ hours after admission would be counted in the 1-day or $\geq 2$-day category, respectively. Also, it is important to note that it was not possible to account for weekday versus weeknight effects. Finally, it was also not possible to evaluate the specific day of surgery after different times to shunting. Nevertheless, the NIS and KID databases have provided useful large national cohorts for a range of studies. Furthermore, the extensive volume of patients available has enabled careful control in multivariate analysis for common confounding factors, including disease severity and hospital demographics.

\section{Conclusions}

Multiple studies have popularized the weekend effect and suggested poorer outcomes among patients admitted on a weekend. Our data indicate that weekend admissions for ventricular CSF diversion were not associated with poorer outcomes when time to shunting was included in 
multivariate analysis. Furthermore, high-volume centers are associated with decreases in mortality rates and increased rates of routine discharge in this cohort.

\section{References}

1. Arnold MA, Chang DC, Nabaweesi R, Colombani PM, Bathurst MA, Mon KS, et al: Risk stratification of 4344 patients with gastroschisis into simple and complex categories. J Pediatr Surg 42:1520-1525, 2007

2. Attenello FJ, Ng A, Wen T, Cen SY, Sanossian N, Amar AP, et al: Racial and socioeconomic disparities in outcomes following pediatric cerebrospinal fluid shunt procedures. J Neurosurg Pediatr 15:560-566, 2015

3. Bell CM, Redelmeier DA: Mortality among patients admitted to hospitals on weekends as compared with weekdays. $\mathbf{N}$ Engl J Med 345:663-668, 2001

4. Buckley D, Bulger D: Trends and weekly and seasonal cycles in the rate of errors in the clinical management of hospitalized patients. Chronobiol Int 29:947-954, 2012

5. Burns EM, Rigby E, Mamidanna R, Bottle A, Aylin P, Ziprin $\mathrm{P}$, et al: Systematic review of discharge coding accuracy. J Public Health (Oxf) 34:138-148, 2012

6. Burns KH, Casey PH, Lyle RE, Bird TM, Fussell JJ, Robbins JM: Increasing prevalence of medically complex children in US hospitals. Pediatrics 126:638-646, 2010

7. Campbell PGMJ, Malone J, Yadla S, Chitale R, Nasser R, Maltenfort MG, et al: Comparison of ICD-9-based, retrospective, and prospective assessments of perioperative complications: assessment of accuracy in reporting. J Neurosurg Spine 14:16-22, 2011

8. Choo S, Papandria D, Zhang Y, Camp M, Salazar JH, Scholz $\mathrm{S}$, et al: Outcomes analysis after percutaneous abdominal drainage and exploratory laparotomy for necrotizing enterocolitis in 4,657 infants. Pediatr Surg Int 27:747-753, 2011

9. Cram P, Hillis SL, Barnett M, Rosenthal GE: Effects of weekend admission and hospital teaching status on in-hospital mortality. Am J Med 117:151-157, 2004

10. Daugaard CL, Jørgensen HL, Riis T, Lauritzen JB, Duus BR, van der Mark $S$ : Is mortality after hip fracture associated with surgical delay or admission during weekends and public holidays? A retrospective study of 38,020 patients. Acta Orthop 83:609-613, 2012

11. Dudley RA, Johansen KL, Brand R, Rennie DJ, Milstein A: Selective referral to high-volume hospitals: estimating potentially avoidable deaths. JAMA 283:1159-1166, 2000

12. Fehlings MG, Vaccaro A, Wilson JR, Singh A, W Cadotte D, Harrop JS, et al: Early versus delayed decompression for traumatic cervical spinal cord injury: results of the Surgical Timing in Acute Spinal Cord Injury Study (STASCIS). PLoS One 7:e32037, 2012

13. Flores G: Technical report-racial and ethnic disparities in the health and health care of children. Pediatrics 125:e979e1020, 2010

14. Freemantle N, Richardson M, Wood J, Ray D, Khosla S, Shahian D, et al: Weekend hospitalization and additional risk of death: an analysis of inpatient data. J R Soc Med 105:74-84, 2012

15. Goldstein SD, Papandria DJ, Aboagye J, Salazar JH, Van Arendonk K, Al-Omar K, et al: The "weekend effect" in pediatric surgery - increased mortality for children undergoing urgent surgery during the weekend. J Pediatr Surg 49:10871091,2014

16. Gologorsky Y, Knightly JJ, Lu Y, Chi JH, Groff MW: Improving discharge data fidelity for use in large administrative databases. Neurosurg Focus 36(6):E2, 2014

17. Halm EA, Lee C, Chassin MR: Is volume related to outcome in health care? A systematic review and methodologic critique of the literature. Ann Intern Med 137:511-520, 2002

18. Hixson ED, Davis S, Harrison AM: Pediatric intensive care unit mortality: is it better 9 to 5? Pediatr Crit Care Med 7:188-189, 2006 (Letter)

19. Mikulich O, Callaly E, Bennett K, O'Riordan D, Silke B: The increased mortality associated with a weekend emergency admission is due to increased illness severity and altered case-mix. Acute Med 10:182-187, 2011

20. Mukherjee D, Kosztowski T, Zaidi HA, Jallo G, Carson BS, Chang DC, et al: Disparities in access to pediatric neurooncological surgery in the United States. Pediatrics 124:e688e696, 2009

21. Patwardhan RV, Nanda A: Implanted ventricular shunts in the United States: the billion-dollar-a-year cost of hydrocephalus treatment. Neurosurgery 56:139-145, 2005

22. Salazar JH, Yang J, Shen L, Abdullah F, Kim TW: Pediatric malignant hyperthermia: risk factors, morbidity, and mortality identified from the Nationwide Inpatient Sample and Kids' Inpatient Database. Paediatr Anaesth 24:1212-1216, 2014

23. Simon TD, Berry J, Feudtner C, Stone BL, Sheng X, Bratton SL, et al: Children with complex chronic conditions in inpatient hospital settings in the United States. Pediatrics 126:647-655, 2010

24. Smith ER, Butler WE, Barker FG II: In-hospital mortality rates after ventriculoperitoneal shunt procedures in the United States, 1998 to 2000: relation to hospital and surgeon volume of care. J Neurosurg 100 (2 Suppl Pediatrics):90-97, 2004

25. Stone ML, Lapar DJ, Kane BJ, Rasmussen SK, McGahren ED, Rodgers BM: The effect of race and gender on pediatric surgical outcomes within the United States. J Pediatr Surg 48:1650-1656, 2013

26. Venkataramana NK, Mukundan CR: Evaluation of functional outcomes in congenital hydrocephalus. J Pediatr Neurosci 6:4-12, 2011

27. Vincent JL, Rello J, Marshall J, Silva E, Anzueto A, Martin $\mathrm{CD}$, et al: International study of the prevalence and outcomes of infection in intensive care units. JAMA 302:2323-2329, 2009

\section{Disclosure}

This study was supported in part by the 2014-2015 Alpha Omega Alpha (AOA) Carolyn Kuckein Medical Student Research Fellowship. Its contents are solely the responsibility of the authors and do not necessarily represent the official views of the AOA.

\section{Author Contributions}

Conception and design: Attenello, Christian, Wen, Mack. Analysis and interpretation of data: Attenello, Wen, Cen, Krieger. Drafting the article: Attenello, Christian, Wen, Cen. Critically revising the article: Zada, Kiehna, Krieger, McComb, Mack. Reviewed submitted version of manuscript: all authors. Approved the final version of the manuscript on behalf of all authors: Attenello. Statistical analysis: Attenello, Wen, Cen, Zada. Administrative/technical/material support: Mack. Study supervision: Attenello, Krieger, McComb, Mack.

\section{Supplemental Information}

\section{Previous Presentation}

Portions of this work were presented at the American Association of Neurological Surgeons/Congress of Neurological Surgeons Joint Section on Pediatric Neurosurgery held in Amelia Island, FL, on December 4, 2014.

\section{Correspondence}

Frank J. Attenello, Keck School of Medicine of USC, University of Southern California, 1520 San Pablo St., Ste. 3800, Los Angeles, CA 90033. email: attenell@usc.edu. 